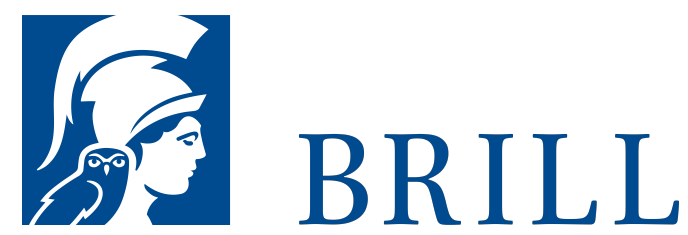

\title{
Respekt und Anerkennung
}

Author: Susanne Schmetkamp

Ob es um den Kopftuchstreit geht oder um die Bedeutung von anständig bezahlter Arbeit, um die Pflichten gegenüber Armen oder um den Umgang mit Tieren und der Natur: 'Respekt' und 'Anerkennung' gehören zu den wichtigsten moralischen Begriffen unserer Zeit. In allen Fällen geht es grundlegend um die Frage, was Menschen einander und anderen Lebewesen moralisch schulden und warum. Allerdings ist in der philosophischen Diskussion vielfach unklar, was die Begriffe jeweils bedeuten und ob sie konzeptionell zusammenpassen. Es ist daher ein Anliegen dieses Buches, die Begriffe grundlegend zu klären, eine vermeintliche Konkurrenz aufzulösen und beide Prinzipien in eine Konzeption zu integrieren. Der erste Begriff 'Respekt' ist dabei als ein basales normatives Prinzip zu verstehen, welches sich auf fundamentale moralische Ansprüche richtet, das heißt im Fall von Menschen auf ihren Anspruch, in ihrer Würde, ihrer Autonomie, ihrer Freiheit und ihren grundlegenden Interessen geachtet zu werden. Allein dies reicht aber für ein würdevolles und gutes Leben nicht aus: Der zweite Begriff der 'Anerkennung' geht darüber hinaus und richtet sich auf konkrete Bedürfnisse und Leistungen. Berücksichtigt man dann noch die Wichtigkeit von verwandten moralischen Einstellungen wie Toleranz, Rücksicht und Mitgefühl, so entsteht ein anspruchsvolles multikriterielles Ethikmodell, welches adäquat auf...

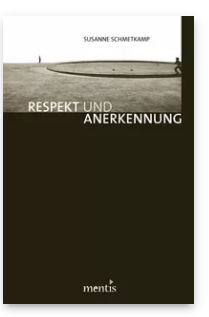

Pages: 234

Seiten

Language:

German

Subjects:

General,

Philosophy

Publisher: Brill | mentis

E-Book (PDF)

Released online:

o1 Feb 2012

ISBN: 978-3-

95743-942-O

List price

USD $\$ 52.00$

Paperback

Publication date:

o1 Feb 2012

ISBN: 978-3-

89785-731-5

List price

USD $\$ 52.00$ 
For more information see brill.com

Order information: Order online at brill.com +44330 333 0049 | customerservices@brill.com Submission information: brill.com/authors

Titles published by Brill | Fink, Brill | mentis or Brill | Schöningh: +49(o)715413279216| brill@brocom.de 